Very similar points were raised by the authors of the second paper, who dealt specially with the head design and with easily handled, quick-change tape 'cartridges'.

The final paper on the first day of the Convention, presented by Mr. J. Moir, discussed cinema stereophony. It is characteristic of cinema systems that they have used $3,4,5$ or even 6 loudspeakers, as opposed to the usual pair of domestic systems. Now with two microphones, only two-point samples of a continuous sound field in the studio are taken, so that the two spaced loudspeakers in your living-room set up a kind of diffraction pattern; this is perhaps more or less correct if you sit in the middle, but not if you sit to one side. Cinema audiences, however, occupy a wide angle, giving corresponding difficulties. One might have hoped that this greater number of spaced microphones would be used to give a more accurate simulation of the studio sound field, but Mr. Moir pointed out that studio personnel have not, in the main, understood the true problem. Most film recordings have used single-track technique, merely switching the sound image about the screen to be roughly coincident with the photographic image, by potentiometer control of the recording level from each microphone: a difficult proceeding if two actors speak simultaneously.

An evening session was devoted to broadcast stereophony. Mr. D. E. L. Shorter stressed the difficulties of 'compatibility'-conventional one-channel reception of an intended stereophony broadcast--and the technical difficulties of modulating a single carrier wave by two sources. Dr. W. S. Percival described an ingenious stereophonic system in which the two channels convey $(a)$ the main acoustic content, (b) the acoustic direction clues, the latter requiring very low information rates indeed; he quite rightly observed that our sense of direction is most sensitive to transient sounds, and his system takes maximum notice of these.

Two papers were delivered on the second day dealing with disk recording. Mr. Dutton referred to internationally agreed standards, both of cutting and pick-up techniques. The most-favoured system, called the $45 / 45$ system, uses orthogonally placed needles at $45^{\circ}$ to the vertical. For best performance, minimum wear, cross-talk, etc., fully mechanical standards have now been set up. Great attention is also being paid to improvements in cutter and pick-up design, for better reproduction and easier manufacture, a topic dealt with in some detail by later speakers.

The Convention closed with a lively discussion, admirably refereed by Mr. Moir, which provided as much interest as some of the main proceedings. Perhaps the Institution of Electrical Engineers can be persuaded to present another Convention later. dealing with principles and fundamental problems rather than so much with design of apparatus. Engineers have gone a long way in this field on inadequate theory, or on none at all. This Convention showed the need now to be pressing.

Colin CherRy

\title{
INDUSTRIAL PHOTOGRAPHIC AND TELEVISION EXHIBITION
}

$\mathrm{T}$ HE Industrial Photographic and Television Exhibition, which was held at the Royal Albert Hall during April 20-24, was sponsored and organized by the Financial Times. It was stated that "the object of the exhibition was to show executives the way in which photography can aid them in many stages of the industrial process or commercial activities".

Throughout the duration of the exhibition a number of lectures were given each day on the use of photography and television in the factory, the office, training and advertising.

The most obvious use of photography is its ability to record events for future reference. A photograph can store, in one instant of time, much more information than an observer could absorb-information the importance of which may not even be appreciated at the time. Such records can be examined in detail and at leisure at a later date. They can also be compared with others taken at different times, in order to find similarities and differences, as in astronomy.

In addition, photography can extend the field of human observation. If an event lasts only a fraction of a second, high-speed photography can be used to slow the action down. On the other hand, some changes are difficult to follow because they occur so slowly. By using time-lapse photography, the timescale can be compressed and the whole cycle of action presented in a few minutes or less.

Furthermore, sensitized photographic materials are sensitive to many forms of radiation to which the eye does not respond in a useful manner, such as infra-red and ultra-violet radiation, $\alpha_{-}, \beta-, \gamma-$ and $\mathrm{X}$-rays and atomic particles.

$X$ - and $\gamma$-rays are used in radiography, which is a non-destructive method of examining the internal structure of a wide range of objects, including human beings. From X-ray and electron diffraction patterns information can be obtained about the fine structure of materials, and in the electron microscope the use of an electron beam enables greater resolution to be obtained than with the optical microscope.

Special emulsions have been developed to help the nuclear physicist record the tracks of particles such as electrons, protons, mesons, etc., moving at high speeds. From these records he gains knowledge of atomic and nuclear structure.

The most striking feature of the exhibition was a large display of excellent black-and-white and coloured prints illustrating the uses to which photography could be put in industry, research, documentation and advertising.

Among these was a set of prints taken by reflected polarized light showing the growth of magnetic domains on the surface of a metal with increasing magnetic field (International Computers and Tabu. lators, Ltd.).

Examples of high-speed photography included a study of spray formation from high-pressure jets (Babcock and Wilcox, Ltd., and John Thornycroft, Ltd.). Another series of photographs illustrated a method of demonstrating fluid-flow by recording the paths taken by numerous small air bubbles suspended in a liquid. The apparatus was illuminated from one side by a flash bulb through a narrow slit so that a 
thin lamina perpendicular to the camera axis was photographed (Harold. White, for the Power Gas Corporation, Ltd.). The Bowater Paper Corporation, Ltd., exhibited a print taken at 1/8000th of a second showing the fluid pulp on the wire mesh of a papermaking machine.

Other pictures showed the use of enamel for revealing the pattern of strain in metals (A. V. Roe, Ltd.), photoelastic stress patterns in gears and pawls (International Computers and Tabulators, Ltd.), the ultrasonic testing of metals (Steel Co. of Wales) and recording of cracks in concrete (Babcock and Wilcox, Ltd.). The last firm also showed photomicrographs of metal structure.

Probably the stand which was best arranged to enlighten the hypothetical executive was that of Pye, Ltd. It was divided into a series of cubicles, each one of which showed an application of closedeircuit television, such as the transmission of printed. information or instrument dial readings or the examination of machinery in operation in inaccessible or inconvenient positions. Details were also given of a special camera designed to operate inside a nuclear reactor. Similar equipment was also exhibited by Marconi Wireless Telegraph Co., Ltd., for traffic observation and control.

Rank Cintel, Ltd., were demonstrating a threechannel colour-television apparatus and a video tape recorder. They also showed how television techniques could be applied to photographic printers and enlargers to adjust the contrast of a negative to improve print quality.

Decca, Ltd., showed a data-transmitting system which used a cathode-ray tube as a scanner with a photomultiplier pick-up tube.
The three photographic firms who exhibited featured document copying and reproduction. Gevaert, Ltd., showed examples of the 'Gevacopy' process which utilizes silver image transfer for producing a few copies. If a larger number are required then an offset printing plate on aluminium can be prepared. Ilford, Ltd., demonstrated a range of machines for using 'Azoflex' paper. This is a dye-coupling process which is capable of producing either as small or as large a number of copies as needed. On the Kodak stand was to be found the 'Verifax' process. This uses a layer which is hardened by light and afterwards pigmented. Any unhardened gelatine on the 'negative' can be transferred, more than once, to other sheets of paper to obtain several copies. Also shown on this stand were the 'Statfile' and 'Recordak' machines. A new model of the latter enables both sides of a sheet of printed material to be recorded side by side on a strip of film in one passage through the machine.

These firms also showed examples of radiography, colour transparencies and prints, etc., illustrating their uses in various fields. Ilford, Ltd., had a compact processing unit for $35,45,60$ and $70 \mathrm{~mm}$. film, which should be very useful to laboratories which employ oscillograph recorders, etc.

On other stands a wide variety of photographic equipment and chemicals could be seen : cameras (still and ciné), lenses, lighting units, timers, printers, enlargers, etc. John Hadland and Co. offered a complete service for high-speed photography. Many stands offered projectors for still and ciné pictures, with and without a commentary in sound for instruction, sales promotion, demonstration and advertising.

R. J. HeRCOCK

\section{CHELSEA COLLEGE OF SCIENCE AND TECHNOLOGY}

\section{NEW BUILDING}

\begin{abstract}
1 NEW wing was opened at Chelsea College of A Science and Technology on April 28 by Lord Adrian. The building was planned a number of years ago before the status of the College was changed and is thus relatively small and does not allow for any increase in social amenities for the College. Plans for further buildings on adjacent sites which will provide residential and social accommodation as well as a completely new Department of Chemistry are already well advanced. A new independent College of Art is also to be built opposite the present College building. In due course the School of Art, which now forms part of the College, will occupy the new building and release accommodation which will be adapted for use by the remaining departments of the College.
\end{abstract}

The present extension, which provides an additional floor area of 17,913 sq. ft., takes the form of a fourstory block running roughly from east to west and facing north to Chelsea Square, with a two-story addition facing inwards to the courtyard of the College. A gap on the second floor of the old West Wing has also been closed by the building of a new zoological laboratory and a smaller staff research laboratory. The main new building provides a laboratory, lecture room, and two store-rooms for physics, six classrooms, staff and office accommodation for mathematics, a large teaching laboratory, two research laboratories, a balance room and a lecture room for chemistry, and a studio, lithography room, store and students' rest room for art. A new students' common room is also provided, but this and the new Art School accommodation is merely exchanged for equivalent space vacated for use by the Department of Botany and Zoology and the College Library. Other rooms vacated by departments occupying the new wing will also be adapted for use by the School of Pharmacy and the Departments of Geology, Physiology and Pharmacology.

In introducing Lord Adrian, the chairman of the Governing Body, Mr. John Townsend, directed attention to the fact that the College was the only college of advanced technology which did not possess an engineering department and the only one which did possess a department of physiology. Lord Adrian referred to the important and expanding fields of training and research which come within the scope of the work of the College. While the need for many more trained engineers was well recognized, there was some danger of neglect of the biological side. Chelsea was well placed, with its large School of Pharmacy and its other science departments, to help in satisfying this need. He likened the present boom period for science to the time when Gresham College was founded in the City of London and the Royal
Society began its existence. At that time there was 